\title{
Radiant Temperatures
}

\section{of Hair Surfaces}

\section{AARON N. MOEN}

Highlight: The radiant temperatures $\left(T_{\mathbf{r}}\right)$ of the surfaces of winter pelage of white-tailed deer, mule deer, snowshoe hare, cottontail rabbit, and red fox decrease with a decrease in air temperature $\left(T_{\mathrm{a}}\right)$ and an increase in wind velocity (U). The relationship between $T_{\mathrm{r}}$ and $T_{\mathbf{a}}$ is linear, but nonlinear for $T_{\mathrm{r}}: U$. Changes in the lower velocities have a relatively greater effect than changes in the higher velocities. The variation between species results in considerable overlap; the use of thermal scanning techniques for censusing of these different species is doubtful under most field conditions.

The author is associate professor, wildlife ecology, and principal investigator, BioThermal Laboratory, Department of Natural Resources, New York State College of Agriculture and Life Sciences, a Statutory College of the State University, Cornell University, Ithaca, New York.

This work has been funded by the New York State Department of Environmental Conservation under Federal Aid Pittman-Robertson Project W-124-R "Energy Relationships of Homeotherms to Their Environment" at the BioThermal Laboratory and the Agricultural Experiment Station, Cornell University, Various aspects of the work were completed by D. S. Stevens, F. L. Jacobsen, and W. P. Armstrong. Lynda $L$. Marrone assisted in typing and editing the manuscript.

Manuscript received January 5, 1974. 
The radiant temperature of a surface is the temperature which is effectively communicating with the thermal environment and represents an integration of the energy emitted. It is used when calculating the amount of energy emitted from a surface with equation (1):

$$
\mathrm{Q}_{\mathrm{r}}=\sigma \epsilon \mathrm{T}_{\mathbf{r}}{ }^{4}
$$

where

$$
\begin{aligned}
& \mathrm{Q}_{\mathrm{r}}=\text { radiant energy emitted } \\
& \sigma=\text { the Stefan-boltzman constant } \\
& \epsilon=\text { emissivity; the fraction of the } \\
& \text { black surface emissive power } \\
& \mathrm{T}=\text { temperature }\left({ }^{\circ} \mathrm{K}\right)
\end{aligned}
$$

When the energy emitted is known, equation (1) can be rearranged to give the radiant temperature $T_{r}$, as in equation (2):

$$
\mathrm{T}_{\mathrm{r}}=\sqrt[4]{\frac{\mathrm{Q}}{\sigma \epsilon}}
$$

Radiant temperatures are being used extensively in two ways, including: (1) energy balance calculations and.(2) censusing applications. Both applications are of interest to wildlife and range managers. The former is useful when analyzing the effects of weather on free-ranging animals and in determining shelter and food requirements; the latter has obvious importance in population ecology and management. This paper describes the relationship between radiant temperature, air temperature, and wind for five different mammals, with a conclusion relating to the possibilities of identifying these species by infrared detection in the field.

The feasibility of using infrared radiation detectors for censusing big game animals has been tested by Croon et al. (1968) and Parker (1972). Early background information was provided by Marble (1967) and Moen (1968). The general conclusion reached by Parker (1972) is that thermal scanning [infrared detection] remains a feasible technique, but success is dependent on the sophistication of the equipment, physical characteristics of topography, and the ambient thermal environment. The thermal characteristics of the target species are a major consideration also; deer were frequently mistaken for antelope (Parker and Driscoll, 1972).

Experiments in two wind tunnels at the BioThermal Laboratory have shown that most of the change in the radiant temperature of a hair surface exposed to sudden changes in wind velocity occurs in a few seconds. The changes are virtually complete within two minutes (Moen and Jacobsen, 1974). The effects of wind on $T_{r}$ in relation to air temperature has been measured on winter pelage from the trunks of white-tailed deer (Odocoileus virginianus); mule deer (O. hemionus), red fox (Vulpes fulva), snowshoe hare (Lepus americanus), and cottontail rabbit (Sylvilagus floridanus).

\section{Measurement Techniques}

Radiant temperatures are measured in the wind tunnels with an infrared thermometer (Model IT-3, Barnes Engineering) positioned over the raw pelt placed on a substrate heated to $38^{\circ} \mathrm{C}$ ( $\simeq$ body temperature). Wind velocities from 0-630 $\mathrm{cm} / \mathrm{sec}(0$ to $14 \mathrm{mi} / \mathrm{hr})$ were tested in the larger tunnel, and $0-360 \mathrm{~cm} / \mathrm{sec}(0$ to $8 \mathrm{mi} / \mathrm{hr})$ in the smaller. The larger tunnel has an experimental section $1 \mathrm{~m}$ wide, $1 \mathrm{~m}$ high, and $2 \mathrm{~m}$ long; the smaller tunnel, $15 \mathrm{~cm}$ wide, $16 \mathrm{~cm}$ high, and $60 \mathrm{~cm}$ long. The interior walls of the experimental sections are painted with 3M Nextel Velvet coating (101-C10 Black). The quoted emissivity of this paint is 0.98 or better at wavelengths from 2 to 35 microns. The techniques are further described and illustrated in Moen (1973).

\section{Results and Discussion}

Radiant temperatures are linearly related to air tempera-

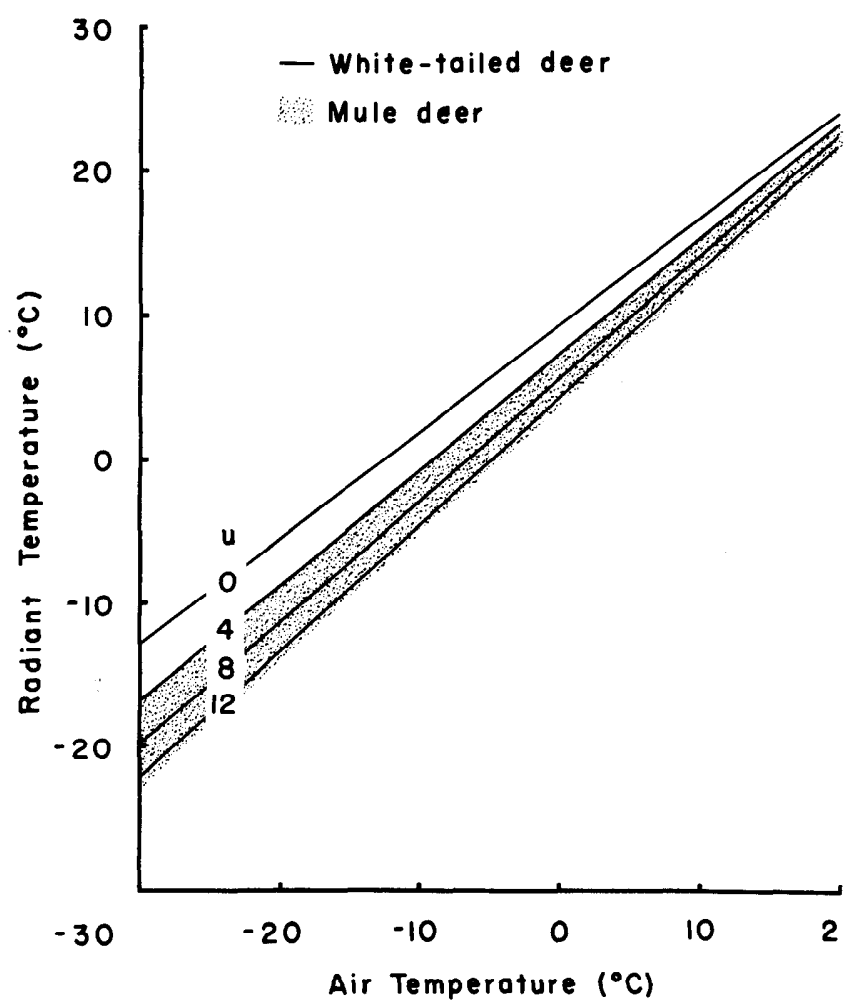

Fig. 1. Radiant temperature in relation to air temperature for whitetailed deer $\left(N_{\mathrm{y}}=555\right)$ and mule deer $\left(N_{\mathrm{y}}=22\right)$ pelts exposed to a range of wind velocities.

tures. No differences were observed for white-tailed deer when the hair orientation was with and against the free-stream flow field. Wind effects are nonlinear, with the lower velocities having a relatively greater effect. A single predictive equation for $T_{r}$ on the trunk of white-tailed deer is (From Stevens 1972):

$$
\mathrm{T}_{\mathrm{r}}=\left[\mathrm{e}^{2.26-0.064 \mathrm{U}}\right]+\left(\left[\frac{38-\left(\mathrm{e}^{2.26-0.064 \mathrm{U}}\right)}{38}\right]\left[\mathrm{T}_{\mathrm{a}}\right]\right)
$$

where

$$
\begin{aligned}
\mathrm{T}_{\mathrm{r}} & =\text { radiant temperature }\left({ }^{\circ} \mathrm{C}\right) \\
\mathrm{U} & =\text { wind velocity }(\mathrm{mi} / \mathrm{hr}) \\
\mathrm{T}_{\mathrm{a}} & =\text { air temperature }\left({ }^{\circ} \mathrm{C}\right)
\end{aligned}
$$

The regression lines are shown in Figure 1. The shaded area in Figure 1 shows the radiant temperature range for mule deer winter pelts for $U=45$ to $360 \mathrm{~cm} / \mathrm{sec}(1$ to $8 \mathrm{mi} / \mathrm{hr})$ in the small tunnel. The overlap is nearly complete; there appears to be little or no difference between the results for these two species. The equations, adjusted through $38^{\circ} \mathrm{C}(\simeq$ body temperature), for the outer limits of the mule deer data are $Y=38+0.804(\mathrm{X}-38)$ for $45 \mathrm{~cm} / \mathrm{sec}$ and $Y=38+0.889$ $(X-38)$ for $360 \mathrm{~cm} / \mathrm{sec}$.

For the other species, values for $b_{\max }$ and $b_{\min }$ in the regression equation are $0.834(45 \mathrm{~cm} / \mathrm{sec})$ and $0.942(360$ $\mathrm{cm} / \mathrm{sec}), 0.778$ and 0.883 , and 0.641 and 0.827 for the snowshoe hare, cottontail and red fox, respectively (Fig. 2). Note the amount of overlap; all of these species appear thermally similar under some wind conditions. Further, the white-tailed deer and mule deer data in Figure 1 fall in the area of greatest overlap.

The high degree of similarity in the $T_{r}: T_{a}$ relationships for these five species when exposed to a range of wind velocities common in their natural habitats indicates that the identification of species by thermal scanning techniques in censusing 


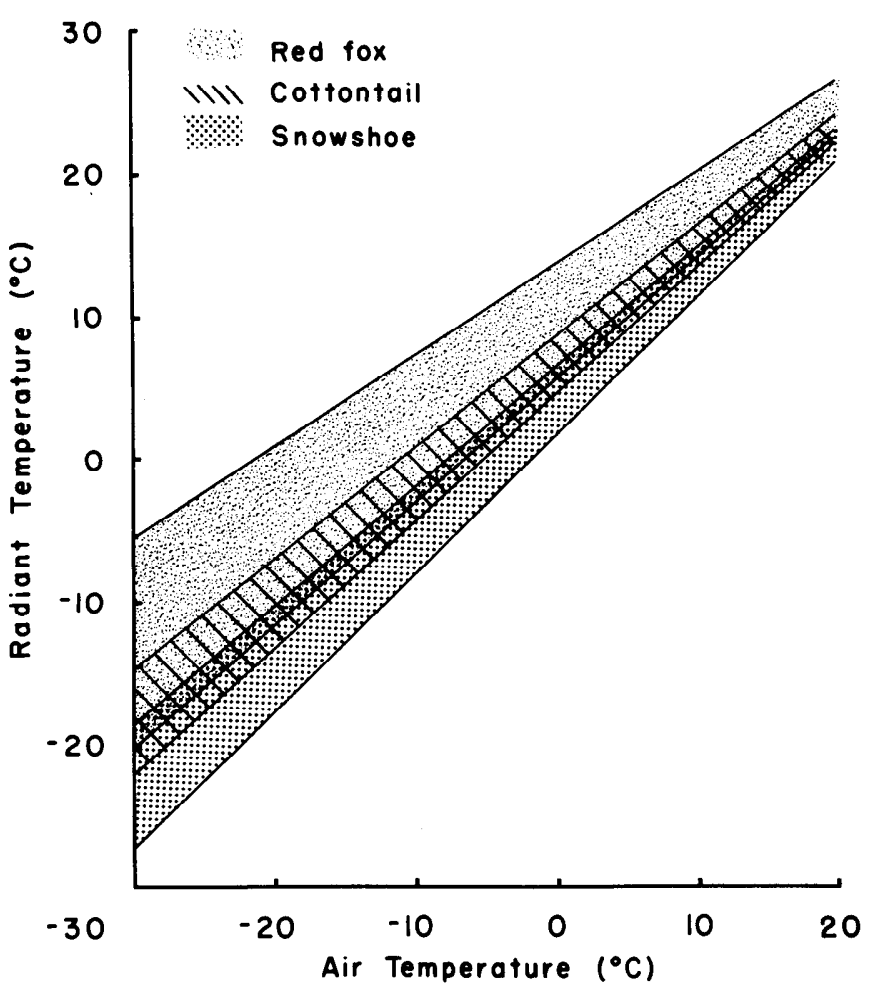

Fig. 2. Radiant temperature in relation to air temperature for three pelts from three species ( $N_{\mathrm{y}}=9$ for each species) exposed to wind velocities from $1 \mathrm{mi} / \mathrm{hr}(45 \mathrm{~cm} / \mathrm{sec})$ to $8 \mathrm{mi} / \mathrm{hr}(360 \mathrm{~cm} / \mathrm{sec})$. Maximum and minimum values for $\mathbf{b}$ are given in the text.

applications is hardly feasible. Additional variation due to the effects of solar radiation (all of these tests were conducted in wind tunnels with uniform radiation from the walls), and variations in the subskin temperature due to local tissue metabolism and vascular changes, would make the thermal image even more dynamic. Vegetative cover would diffuse the thermal image also. Larger target species, deer, contribute more to a thermal signal than the smaller hare, rabbit, and fox, given equal spatial resolution of the scanning equipment. Since vegetative cover may occlude and diffuse part or all of the image, the apparent thermal image may be more a function of behavior and habitat characteristics than numbers of each species present. In conclusion, the feasibility of thermal scanning for censusing purposes is doubtful in all but the simplest of habitats.

\section{Literature Cited}

Croon, G. W., D. R. McCullough, C. E. Olson, Jr., and L. M. Queal. 1968. Infrared scanning techniques for big game censusing. J. Wildl. Manage. 32:751-759.

Marble, H. P. 1967. Radiation from big game and background: A control study for infrared scanner census. MS Thesis. Univ. of Montana, $88 \mathrm{p}$.

Moen, A. N. 1968. Surface temperatures and radiant heat loss from white-tailed deer. J. Wildl. Manage. 32:338-344.

Moen, A. N. 1973. Wildlife ecology: An analytical approach. W. H. Freeman and Company, San Francisco. 458 p.

Moen, A. N. and F. L. Jacobsen, 1974. Changes in radiant temperature of animal surfaces with wind and radiation. J. Wildl. Manage. 38: (In press).

Parker, H. D., Jr. 1972. Airborne infrared detection of deer. PhD Thesis. Colo. State Univ., Fort Collins, $186 \mathrm{p}$.

Parker, H. D. and R. S. Driscoll. 1972. An experiment in deer detection by thermal scanning. J. Range Manage. $25: 480-481$.

Stevens, D. S. 1972. Thermal energy exchange and the maintenance of homeothermy in white-tailed deer. PhD Thesis. Cornell Univ., Ithaca, N.Y. 231 p. 